\title{
Advanced Analytical Electron Microscopy: New Perspectives on Real Materials
}

\author{
M. G. Burke ${ }^{1}$, S. J. Haigh ${ }^{1}$, J. J. H. Lim ${ }^{1}$, and A. Janssen ${ }^{1}$ \\ ${ }^{1 .}$ Material Performance Centre and the Electron Microscopy Centre, School of Materials, The University \\ of Manchester, Manchester (UK)
}

The recent advances in XEDS afforded by new Si drift detector (SDD) geometries and new analytical transmission electron microscope platforms have enabled major progress in the characterisation of both conventional metals/alloys and complex materials with nanoscale features that have a dramatic effect on material performance. In particular, detailed microchemical analyses that had previously only been possible using techniques such as atom probe field-ion microscopy (for compositional and structural information) or 3D atom probe analysis (compositional data) are now very amenable to advanced Analytical Electron Microscopy (AEM) analysis. The increased solid angle for X-ray energy dispersive spectroscopy (XEDS) data collection has resulted in greatly reduced data acquisition times for spectrum imaging, enabling the detection of nm-scale segregation and precipitation. Thus, these new systems can be readily applied to address "conventional" materials issues such as precipitation behaviour, embrittlement and environmentally-assisted fracture. To demonstrate the improved capabilities for materials research using STEM-XEDS in new advanced AEMs, we have examined both conventional precipitation-hardened Ni-base Alloy 625, and a neutron-irradiated low alloy steel weld.

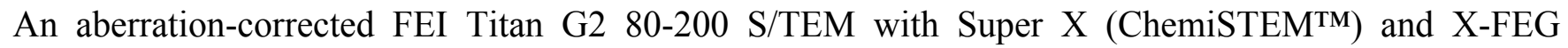
operated at $200 \mathrm{kV}$ was used in this study. All XED spectrum images were acquired with a beam current of $1 \mathrm{nA}$; all samples were conventional electropolished thin-foils. Alloy 625, with a nominal composition (wt.\%) of $20 \mathrm{Cr}-10 \mathrm{Mo}-4 \mathrm{Fe}-3.5 \mathrm{Nb}-0.3 \mathrm{Ti}-0.3 \mathrm{Al}-0.05 \mathrm{C}-$ bal Ni, is generally used in the aged (high strength) condition. During ageing in the temperature range $\sim 650-800^{\circ} \mathrm{C}, \mathrm{DO}_{22^{-}}$ ordered $\gamma$ " $\left(\mathrm{Ni}_{3}(\mathrm{NbTi})\right)$ precipitates form, leading to the increased strength of the alloy. These $\gamma$ " precipitates are disc-shaped and form so that the disc is parallel to $\{100\}$ in the fec matrix. The HAADF and XED spectrum images (acquired for $27 \mathrm{~min}$ ) in Figure 1 clearly shows the 3 variants of $\gamma$ " precipitates formed during ageing at $650^{\circ} \mathrm{C}$ for $100 \mathrm{~h}$. Using HR-STEM, it was possible study the coherent (001) interface of the precipitate and visualize the pure $\mathrm{Ni}$ and mixed $\mathrm{Ni}-\mathrm{Nb}$ planes in the $\gamma^{\prime \prime}$, as shown in Figure 2. The XED spectra - both sum spectrum and discrete spot analyses in the precipitates - demonstrated that there was detectable Al in the $\gamma$ ". Such data are useful for alloy design/optimization.

The improved solid angle of the Super $\mathrm{X}$ configuration also enabled the direct visualization of irradiation-induced Mn-Ni-enriched clusters in neutron-irradiated low alloy steel welds. These features are of great interest because they are associated with the irradiation-induced hardening and embrittlement that can degrade the toughness of the reactor pressure vessel of pressurized water reactors (PWRs). 3D-Atom Probe analysis is generally used to analyze such irradiation-induced features. The Titan "ChemiSTEM" SDD XED spectrum images for $\mathrm{Ni}$ and $\mathrm{Mn}$ in a $1.6 \mathrm{Ni}-1.4 \mathrm{Mn}$ weld clearly show the $\mathrm{Ni}$ and $\mathrm{Mn}$-enriched solute clusters formed during neutron irradiation. These examples highlight the wide applicability of the improved XEDS/microscope system, and will be discussed in this presentation.

References:

[1]The authors thank Matt Smith for technical assistance and support of the Titan G2 80-200 S/TEM provided by HM Government (UK). 

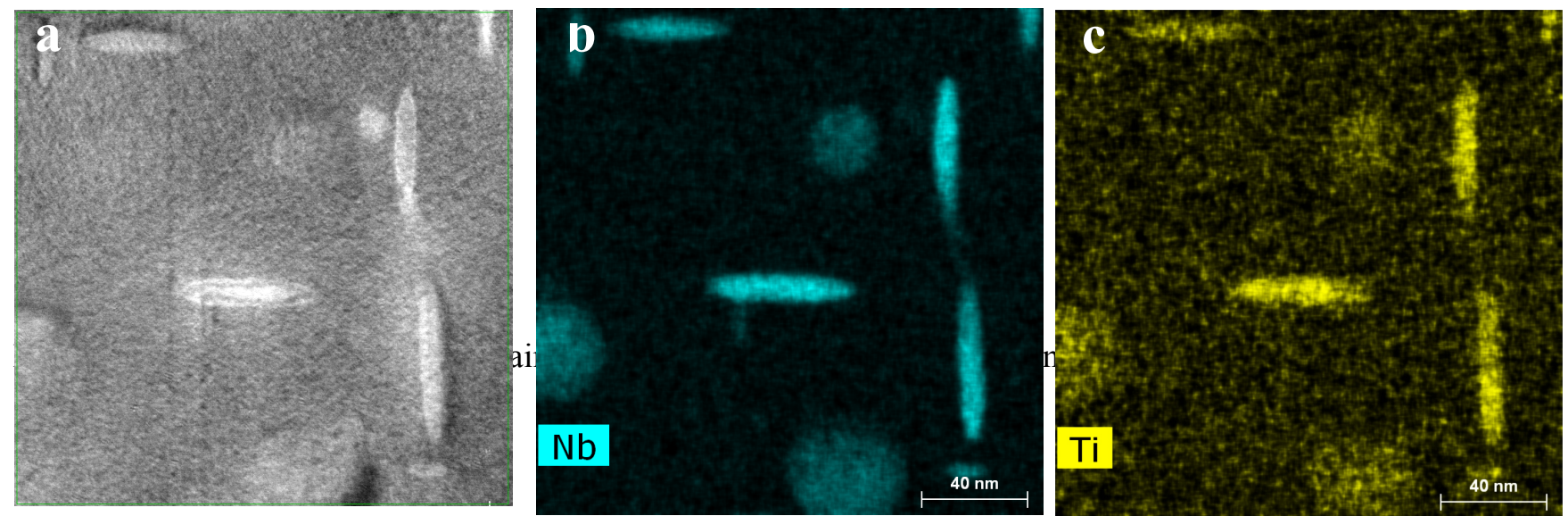

Fig. 1: (a) HAADF image and complementary (b) Nb and (c) Ti XED spectrum images of $\gamma$ " precipitates in aged Alloy 625. All 3 variants of the disk-shaped $\mathrm{DO}_{22}$-ordered precipitates are visible in this [001]-oriented specimen.
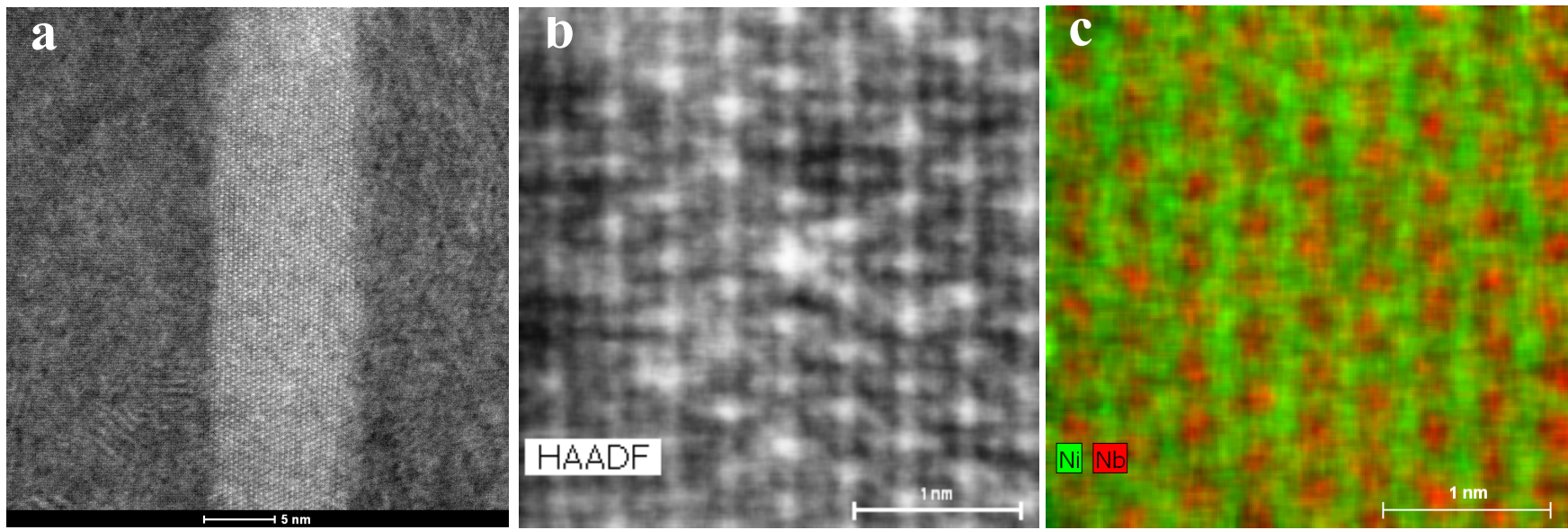

Fig. 2: (a) HR-STEM image of $\gamma$ " precipitate with $\{001\}$ (disc) face parallel to $\{100\}_{\text {matrix. }}$ (b) HAADF and (c) complementary XED spectrum image of $\mathrm{Ni}$ and $\mathrm{Nb}$ showing the pure Ni layers in the ordered $\gamma$ " precipitate.

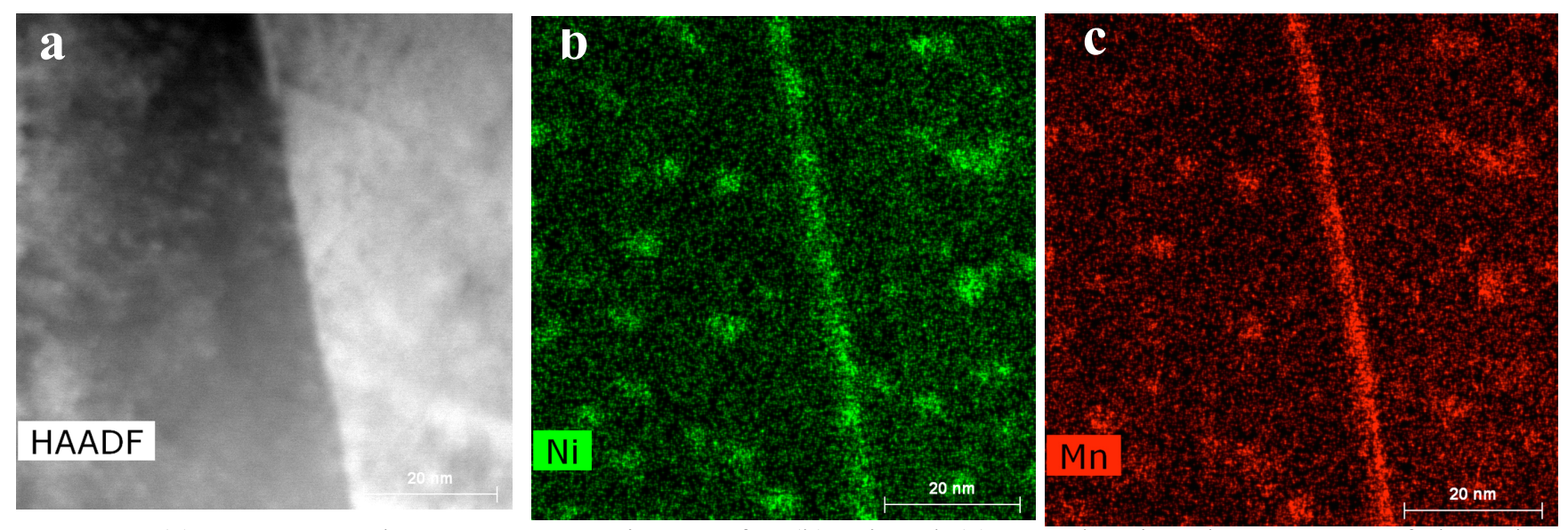

Fig. 3: (a) HAADF and XED spectrum images for (b) Ni and (c) Mn showing the presence of the soluteenriched clusters formed during neutron irradiation. Preferential solute clustering/segregation also occurred at grain boundaries and dislocations. 